\title{
LEVANTAMENTO DE PLANTAS ALIMENTÍCIAS NÃO-CONVENCIONAIS EM CARAGUATATUBA
}

\section{Flávia Cristina Ribeiro Santos ${ }^{1}$}

Karolina Marie Alix Benedictte Van Sebroeck Dória²

Resumo: A maioria das pessoas não tem o conhecimento que as plantas alimentícias não-convencionais (PANC) podem servir de alimento. Pois, de modo geral, são plantas descartadas pelo grande comércio. Este desuso, é sobretudo, devido à falta de informação da sua utilidade e preparo. Há muitas perdas de plantas silvestres que possuem altos valores nutritivos, maiores do que plantas domésticas. O objetivo deste trabalho é realizar o levantamento das espécies de PANC que ocorrem no centro Caraguatatuba-SP. Constatou-se a presença de 13 espécies pertencentes a 11 famílias. A família mais abundante é a Asteraceae com três espécies. As demais contam com apenas uma espécie. A Crespi japonica é a espécie mais comum, sendo encontrada em três das cinco ruas amostradas.

Palavras-chave: Plantas comestíveis silvestres; Etnobotânica; Nutrição.

\footnotetext{
${ }^{1}$ Ciências Biológicas/Centro Universitário Módulo, Brasil. E-mail: flaviacristinaribeirosantos@gmail.com

${ }^{2}$ Ciências Biológicas/Centro Universitário Módulo, Brasil. E-mail: karolina.doria@modulo.edu.br.
} 